\title{
GERMINAÇÃO DE Urochloa brizantha CV. MARANDU APÓS O TRATAMENTO DAS SEMENTES COM FUNGICIDA E ESCARIFICAÇÃO MECÂNICA
}

\author{
Rafael Maris Rodrigues La Vale1, Sandy Breschi Segato², Neimar Rotta Nagano², Daniele Perreti \\ Bettio $^{3}$ \\ ${ }^{1}$ Engenheiro Agrônomo. ${ }^{2}$ Universidade do Oeste Paulista - UNOESTE, Presidente Prudente, SP. ${ }^{3}$ Casa da Agricultura de \\ Emilianópolis, SP. E-mail: sandysegato@hotmail.com
}

\section{RESUMO}

A Brachiaria spp. assim como outras forrageiras, são destinadas principalmente para pastejo, corte, conservação do solo ou uso direto para produção de sementes, na qual é necessária para suprir a cadeira produtiva. Porém o elevado índice de dormência nas sementes de gramíneas e o ataque de fungos dificultam a germinação dessas espécies. Sendo assim, o objetivo deste trabalho foi avaliar a germinação das sementes de Urochloa brizantha, c.v. Marandu, após escarificação mecânica e tratamento com fungicida. O experimento foi conduzido na unidade de beneficiamento de sementes e laboratório de análise de sementes localizado em Presidente Prudente/SP. Avaliou-se a germinação e os valores obtidos foram submetidos à análise de variância e teste de médias usandoTukey, ao nível de $5 \%$ de probabilidade. Concluiu-se que, sementes não escarificadas tratadas com fungicida melhoram a germinação das sementes de Urochloa brizantha cv. Marandu.

Palavras-chave: Forrageira. Escarificação. Dormência. Brachiaria spp. Tetrazólio.

\section{GERMINATION OF Urochloa brizantha CV. MARANDU AFTER TREATMENT OF SEEDS WITH FUNGICIDE AND MECHANICAL SCARIFICATION}

\begin{abstract}
Brachiaria spp. as well as other forages, are mainly intended for grazing, cutting, soil conservation or direct use for seed production, in which it is necessary to supply the productive chair. However, the high dormancy index in grass seeds and the fungus attack make the germination of these species difficult. Therefore, the objective of this work was to evaluate the germination of the seeds of Urochloa brizantha, c.v. Marandu, after mechanical scarification and treatment with fungicide. The experiment was conducted at the seed processing unit and seed analysis laboratory located in Presidente Prudente / SP. The germination was evaluated and the values obtained were submitted to analysis of variance and test of means using Tukey, at the level of $5 \%$ of probability. It was concluded that non-scarified seeds treated with fungicide improved the germination of the seeds of Urochloa brizantha cv. Marandu.
\end{abstract}

Keywords: Forage. Scarification. Dormancy. Brachiaria spp. Tetrazolium.

\section{INTRODUÇÃO}

As áreas de pastagens no Brasil se concentram de forma significativa, devido o alto índice de pecuária no país. Em 2000 a área de pastagem natural era de 25,17\% e pastagem com manejo 7,52\%, já em 2014 a área de pastagem natural diminuiu para 19,42\% e pastagem com manejo $12,12 \%$ (IBGE,2016).

Dentre as forrageiras mais utilizadas está a Brachiaria spp., a qual possui cerca de 100 espécies com amplo habitat, que vão desde a floresta até o semi deserto, com predominância de espécies na Savana (MILES et al., 1996). Aproximadamente $85 \%$ da área de pastagem do Brasil são Colloquium Agrariae, vol. 13, n. Especial, Jul-Dez, 2017, p. 88-92. ISSN: 1809-8215. DOI: 10.5747/ca.2017.v13.nesp.000177 
ocupadas pelo gênero Brachiaria spp., pois é indicada para solos de baixa fertilidade, com acidez e restrições (LUCENA, 2011).

A Brachiaria decumbens, Brachiaria brizantha e Brachiaria ruziziensis tiveram aumento de cultivo em 1970, quando notadas características de boa formação e de viabilidade para áreas de declive, por conta de enraizamento nos nós, proporcionando cobertura vegetal e protegendo de erosões (ALVIN; BOTREL; XAVIER, 2002).

No entanto, o entrave no plantio de espécies de gramíneas é a dormência, fenômeno caracterizado pela ocorrência de sementes viáveis que mesmo em condições ambientais favoráveis não germinam (CARVALHO; NAKAGAWA, 2000).

Alguns tratamentos de quebra de dormência vêm sendo elaborados e testados, como, por exemplo, para dormência tegumentar: uso de água fervente, escarificação química (sementes tratadas com ácido sulfúrico concentrado) e escarificação mecânica (ALVARENGA; FREITAS; TILLMANN, 2012). A escarificação mecânica já surtiu efeitos de superação de dormência em Brachiaria spp. quando se usou lixa manual (TROMBETTA, 2013). Assim também, como o método de escarificação química com ácido sulfúrico que encontra partida pode acelerar a deterioração da semente (CARDOSO et al., 2014).

As informações sobre quebra de dormência em sementes são incipientes e há também precariedade sobre a sanidade das sementes forrageiras comercializadas no Brasil, já que as quebras de dormência as deixariam ainda mais vulneráveis ao ataque de fungos potencialmente patogênicos e fitonematóides, constatando a necessidade de se realizar o tratamento com fungicidas para evitar danos (MALLMANN et al., 2013).

Os danos causados por micro-organismos nas sementes são variáveis, podendo afetar a germinação e o vigor, ou na condução do campo, morte das plantas, podridões e outros aspectos negativos (DIAS; ZANATTA; LUCCA FILHO, 2012). Para reduzir esses efeitos, é realizado o tratamento químico, podendo ser fungicidas e inseticidas conforme a necessidade do lote (CARVALHO; NAKAGAWA, 2000).

De tal forma, se faz pertinentes estudos que abranjam a influência da escarificação quando associada ao uso de produtos químicos para o tratamento de sementes. Assim, o objetivo deste trabalho foi avaliar a germinação das sementes de Urochloa Brizantha, cultivar Marandu, após escarificação mecânica e tratamento com fungicida.

\section{METODOLOGIA}

O experimento foi conduzido em uma unidade de beneficiamento de sementes e laboratório de análise de sementes com foco em gramíneas na cidade de Presidente Prudente/SP. Foi utilizado para os tratamentos sementes da espécie Urochloa brizantha cultivar Marandu, safra 2015/2016. O delineamento experimental empregado foi o inteiramente casualizado com 04 tratamentos e 16 repetições de 100 sementes cada.

Os tratamentos foram com e sem escarificação mecânica e aplicação de fungicida. A escarificação mecânica foi realizada com o atrito de borrachas retirando a gluma das sementes e o produto utilizado para o tratamento foi o fungicida Vitavax Thiram 200sc administrado sempre na dose de $2,5 \mathrm{~mL}+27,5 \mathrm{~mL}$ de água para $1 \mathrm{Kg}$ de sementes. Para a distribuição do fungicida foi utilizado um equipamento com discos giratórios de velocidade, que garantem distribuição homogênea do produto nas sementes. Para secagem as sementes foram depositadas em uma tela com orifícios que garantem a entrada de ar, ficando aproximadamente 1 hora em local aberto, na sombra com temperatura ambiente (em torno de $33^{\circ} \mathrm{C}$ ).

Logo os tratamentos se constituíram em: T01 = Sem escarificação/Sem fungicida; T02 = Sem escarificação/Com fungicida; $\mathrm{T} 03$ = Com escarificação/Sem fungicida; $\mathrm{T04}=$ Com escarificação/Com fungicida. Após a realização dos tratamentos, as amostras foram encaminhas 
para o laboratório, onde cada amostra foi homogeneizada e passou pela análise de pureza, para que a partir dessa análise fossem coletadas aleatoriamente as sementes puras para a realização do teste de germinação.

Para o teste de germinação, 100 sementes de cada repetição foram dispostas em caixas plásticas transparentes, sobre papel de germinação (mata-borrão), com água destilada e acondicionadas a uma temperatura de $34^{\circ} \mathrm{C}$ diurna e $20^{\circ}$ noturna, durante 21 dias, com contagem de plântulas a cada 07 dias e umedecimento quando necessário. Após esse período as sementes que não germinaram passaram pelo teste de tetrazólio para ser identificado o índice de dormência. Neste teste as sementes são pré umedecidas entre papel, incubadas a $30^{\circ} \mathrm{C}$ por 18 horas em estufa úmida e após esse período é feito um corte longitudinal através do embrião e posteriormente a imersão na solução de tetrazólio a $0,2 \%$ por 4 horas a $37^{\circ} \mathrm{C}$ para a avaliação das sementes viáveis, no caso dormentes. Cada repetição obteve um número de sementes para ser encaminhada ao teste de tetrazólio, o que serve apenas para determinar o número de sementes dormentes naquela repetição.

Os resultados dos respectivos tratamentos foram submetidos à Análise de variância e Teste de Tukey, para comparação de médias, ao nível de $5 \%$ de probabilidade. Foi utilizado o programa estatístico Assistat versão 7.7 Beta.

\section{RESULTADOS}

O tratamento "Sem escarificação/Com fungicida" proporcionou maior obtenção de plântulas normais (Tabela 01). Pode-se observar também que após ter realizado a escarificação mecânica nas sementes, a quantidade de sementes mortas pós-germinação apresentou elevação, chegando a ser de 20 a $10 \%$ superior do que as sementes que não foram escarificadas e receberam tratamentos ou não com fungicida, respectivamente.

Em relação à dormência, os tratamentos que não receberam aplicação de fungicida proporcionaram maiores números de sementes dormentes, sendo que o tratamentos "Sem escarificação/Com fungicida" reduziu o nível de dormência das sementes em $80 \%$ (Tabela 01).

TABELA 01 - Resultados de plântulas normais, sementes mortas e dormentes obtidas no teste de geminação em sementes de Urochloa brizantha cv. Marandu sobre a influência de escarificação mecânica e aplicação de fungicida.

\begin{tabular}{|c|c|c|c|}
\hline \multirow[t]{2}{*}{ TRATAMENTOS } & Normais & Mortas & Dormentes \\
\hline & \multicolumn{3}{|c|}{$\%$} \\
\hline Sem escarificação/Sem fungicida & $69 \mathrm{bc}$ & $17 \mathrm{c}$ & $15 \mathrm{a}$ \\
\hline Com escarificação/Sem fungicida & $65 c$ & $21 \mathrm{a}$ & $15 \mathrm{a}$ \\
\hline Sem escarificação/Com fungicida & $78 \mathrm{a}$ & $19 \mathrm{bc}$ & $3 c$ \\
\hline Com escarificação/Com fungicida & $71 \mathrm{~b}$ & $20 a b$ & $9 \mathrm{~b}$ \\
\hline
\end{tabular}

Letras iguais não se diferem pelo Teste de Tukey ao nível de 5\% de probabilidade.

\section{DISCUSSÃO}

A aplicação de fungicida nas sementes proporcionou maior taxa de germinação, resultado este que corrobora com os de Maresciallo e Effgen (2016) que ao avaliarem tratamentos com Carbendazim + thiran, observaram que houve um aumento na velocidade de emergência e maior número de plântulas normais quando comparados ao tratamento sem aplicação de fungicidas em sementes.

O efeito favorável dos tratamentos com Carboxim + thiram sobre a germinação também já haviam sido observados por Marchi et al. (2006) independentemente da presença do isolado de fungos (Fusarium $\mathrm{sp}$ ). 
Em relação à escarificação, notou-se que não ocorreu favorecimento no tratamento apenas escarificado mecanicamente (Tabela 01), no entanto autores como Cruciol et al. (2014) ao testarem outros tipos de escarificação como a química com ácido sulfúrico em Brachiaria humidicola chegaram a conclusão de que há favorecimento na velocidade de germinação, redução de patógenos e se realizado assepsia superficial pode-se aumentar o potencial fisiológico da semente.

No entanto, nota-se que mais estudos devem ser realizados comparando tipos distintos de escarificações em sementes, já que podem surtir efeitos contraditórios entre si e que independente de escarificar ou não, o tratamento com fungicidas proporciona maior obtenção de plântulas normais. Segundo Santos (2010), o uso de fungicidas se torna eficiente no controle de fungos e portanto é favorável ao desenvolvimento de Urochloa spp.

\section{CONCLUSÃO}

Conclui-se que a não escarificação mecânica em sementes de Urochloa brizantha cv. Marandu quando associada ao tratamento de fungicida (Vitavax Thiram 200sc), elevou o número de plântulas normais pós-germinação e reduziu em $80 \%$ a dormência das sementes, proporcionando maior porcentagem de germinação.

\section{REFERÊNCIAS}

ALVARENGA, Emílio Eduardo Curtis; FREITAS, Demócrito Amorim Chiesa; TILLMANN, Maria Ângela André. Dormência em Sementes: Causas e Superação. Pelotas: Universidade Federal de Pelotas, 2012. 27 p. Compilação de Monografias em Ciência e Tecnologia de Sementes.

ALVIN, M. J.; BOTREL, M. de A.; XAVIER, D. F. As principais espécies de Brachiaria utilizadas no País. Juiz de Fora: Comunicado técnico Embrapa 22. Embrapa, 2002.

CARDOSO, E. D., SA, M. E. D., HAGA, K. I., BINOTTI, S., NOGUEIRA, D. C., VALERIO FILHO, W. V. Desempenho fisiológico e superação de dormência em sementes de Brachiaria brizantha submetidas a tratamento químico e envelhecimento artificial. Semina: Ciências Agrárias, [s.l.], v. 35, n. 1, p.21-37, 26 fev. 2014. Universidade Estadual de Londrina.

CARVALHO, N. M.; NAKAGAWA, J. Sementes - Ciência, Tecnologia e Produção. 4. ed. Jaboticabal: Funep, 2000. 588 p.

CRUCIOL, G. C. D. Qualidade fisiológica e sanitária de sementes de forrageira tratadas quimicamente. Enciclopédia Biosfera, Centro Científico Conhecer, Goiânia, v. 10, n. 19, p.1587-1595, 01 dez. 2014.

DIAS, P. R. P.; ZANATTA, Z. C. N.; LUCCA FILHO, O. Importância e Controle de Patógenos associados às Sementes. Pelotas: Universidade Federal de Pelotas, 2012. 597 p. Compilação de Monografias em Ciência e Tecnologia de Sementes.

IBGE. Áreas agrícolas e de pastos com manejo crescem no Brasil. Dez. 2016. Acesso: 02/06/2017

LUCENA, M. A. C. de. Características Agronômicas e estruturais de Brachiaria spp. submetidas a doses e fontes de nitrogênio em solo de cerrado. 2011. $101 \mathrm{f}$. Dissertação (Mestrado) - Curso de Zootecnia, Agência Paulista de Tecnologia dos Agronegócios, Nova Odessa, 2011 
MALLMANN, G., VERZIGNASSI, J. R., FERNANDES, C. D., SANTOS, J. M. D., VECHIATO, M. H., INÁCIO, C. A., \& QUEIROZ, C. D. A. Fungos e nematóides associados a sementes de forrageiras. Summa Phytopathol, Botucatu, v. 29, n. 3, p.201-203, 23 jul. 2013.

MARCHI. C. E., FERNANDES C.D., JeRBA V. DE F., VECHIATO M. H., TRENTINR. A, BUENO M. L. Tratamento de Sementes de Capim-marandu para controle de Fusarium sp. e outros fungos de solo. 2006. Biologico, São Paulo, V. 68 Suplemento. Disponível em: http://www.biologico.sp.gov.br/docs/bio/suplementos/v68 supl/p596-598.pdf Acesso em: 23 maio 2017.

MARESCIALLO, B. G.; EFFGEN, C. F.. Avaliação de diferentes fungicidas no tratamento de sementes de feijoeiro. 2016. Disponível em: http://www.unigran.br/ciencias exatas/conteudo/ed8/artigos/03.pdf Acesso em: 23 maio 2017.

MILES, J.W.; MAASS, B.L; VALLE, C. B.. Brachiaria: Biology, Agronomy and Improvement. CIAT Publication No. 259. Cali, 288 p. 1996.

SANTOS, F. C. Tratamento químico, revestimento e armazenamento de sementes de Brachiaria brizantha cv. Marandu. Revista Brasileira de Sementes, Londrina, v. 32, n. 3, p.69-78, 20 abr. 2010. https://doi.org/10.1590/S0101-31222010000300008

TROMBETTA, Carlos Guilherme. Dormência, vigor e estabelecimento inicial de Brachiaria e Alfafinha. 2013. 52 f. Tese (Doutorado) - Curso de Agronomia, Universidade Federal de Pelotas, Pelotas, 2013. 